Ann. Biol. anim. Bioch. Biophys., I973, 13 (I), I4I-I46.

NOTE

\title{
LES CONSTITUANTS GLUCIDIQUES ET AZOTÉS DES RACINES DE BETTERAVES DE DIFFÉRENTS TYPES
}

\author{
R. JARRIGE et G. FAUCONNEAU * \\ Station de Recherches sur l'Élevage des Ruminants, \\ * Station d'Études des Métabolismes, \\ Centre de Recherches de Clermont-Ferrand, I. N. R. A., \\ Theix, Saint Genès Champanelle \\ 63110 Beaumont
}

\section{RÉSUMÉ}

A l'aide des techniques de chromatographie sur papier, on a dosé les sucres des principales fractions glucidiques (tabl. I) et les acides aminés libres et amides (tabl. 2), de racines de six variétés de betteraves : deux fourragères pauvres en matière sèche, deux fourragères riches en matière sèche, une sucrière et une potagère.

La teneur en saccharose augmente d'une variété à l'autre en même temps que la teneur en matière sèche alors que la teneur en sucres réducteurs diminue. La fraction hémicelluloses est en concentration relativement comparable dans les six variétés; elle est caractérisée par une proportion très élevée d'arabinose. La teneur en cellulose vraie varie en sens inverse de la teneur en matière sèche et en saccharose.

La répartition de l'azote total est relativement semblable pour les six variétés : de $7 \mathrm{I}$ à 81 p. roo sous forme de constituants éthanolo-solubles (acides aminés libres et amides), de 7 à $8 \mathrm{p}$. Ioo sous forme de peptides extraits par l'eau après le traitement par l'éthanol et seulement de ro à $21 \mathrm{p}$. Ioo sous forme de protéines. L'ensemble des acides aminés libres et amides est caractérisé par la prépondérance de la glutamine (de 35 à $50 \mathrm{p}$. 10o) et la faible proportion des acides aminés essentiels.

\section{INTRODUCTION}

Les betteraves sont un aliment de choix pour les ruminants ; elles sont aussi utilisées dans l'alimentation des porcs (Rérat et HenRy, 1964). Demarguiliy (I972) a récemment confirmé qu'elles avaient une digestibilité et une ingestibilité élevée chez le mouton et montré les particularités de leur digestion dans le rumen. A l'occasion de ce travail, il nous a paru utile de publier les résultats que nous avions obtenus dans une étude déjà ancienne (1955) sur la composition chimique comparée de différents types de betteraves. Les méthodes chromatographiques 
sur papier que nous avions utilisées ne sont pas aussi précises que celles qui ont été mises au point depuis cette époque ; cependant nos résultats présentent toujours un certain intérêt, puisqu'il ne semble pas y avoir d'études récentes sur ce sujet.

\section{MATÉRIEL, ET MÉTHODES}

Nous avons choisi six variétés (tabl. I) : deux fourragères pauvres en matière sèche, deux fourragères riches en matière sèche qui sont encore parmi les plus utilisées, une sucrière et une potagère à chair rouge. Les six variétés ont été cultivées dans le même champ d'expérimentation de la Station d'Amélioration des Plantes de Versailles en I955.

L'analyse a porté sur des cossettes congelées qui ont été broyées dans un appareil WaringBlendor. Les sucres ont été dosés sur l'extrait par l'éthanol à $80 \mathrm{p}$. Ioo. Les constituants membranaires ont été fractionnés par des hydrolyses acides sur le résidu obtenu après extraction des constituants solubles dans $l^{\prime}$ eau $\left(80^{\circ} \mathrm{C}\right)$ et des substances pectiques par une solution d'oxalate d'ammonium à 0,5 p. 1oo. Les sucres de l'extrait éthanolique et des hydrolysats acides ont été dosés par colorimétrie après séparation chromatographique sur papier. Ces différentes méthodes, ainsi que les modalités d'expression des résultats, ont été exposées par JARrige (196I). Par ailleurs, les pentosanes ont été dosés par la méthode classique de distillation chlorhydique.

Les constituants azotés solubles ont été extraits quantitativement, d'abord par l'éthanol à $80 \mathrm{p}$. Ioo à $\mathrm{o}^{\circ}$ puis par l'eau à la même température. L'extrait éthanolique contient la totalité des acides aminés libres et des amides et quelques petits peptides; l'extrait aqueux contient les peptides et le résidu les protéines. Les extraits éthanoliques sont purifiés par chromatographie préparative sur colonne d'Amberlite IR I $20\left(\mathrm{H}^{+}\right)$; l'élution quantitative des acides aminés libres et amides est effectuée par l'ammoniaque $2 \mathrm{~N}$ puis par l'ammoniaque $4 \mathrm{~N}$. Les acides aminés libres et amides sont analysés par chromatographie bidimensionnelle quantitative sur papier (Fauconneau et Pion, I966).

\section{RÉSULTATS ET DISCUSSION}

\section{Constituants glucidiques}

L'accroissement de la teneur en matière sèche entre les variétés s'accompagne d'une augmenltation des teneurs en saccharose et en sucres totaux et d'une diminution de la teneur en sucres réducteurs (tabl. I). Ces résultats sont en accord avec les données résumées par BECKER et NEHRING (1969). L'examen chromatographique montre que les sucres alcoolosolubles sont le saccharose et le glucose, avec des traces de xylose et d'arabinose dans les deux variétés les plus riches et dans la variété potagère.

La proportion de la matière sèche extraite par le traitement à l'oxalate d'ammonium est un peu plus élevée pour les variétés fourragères pauvres et surtout pour la variété potagère. Cet extrait, qui correspond en principe aux substances pectiques, est constitué approximativement pour un quart de sucres (arabinose, galactose et glucose), tout au moins dans les deux variétés Red Otofte et Kuhn. Cela ressort d'une comparaison que nous avons effectuée sur ces deux variétés de la composition glucidique du résidu obtenue avant et après le traitement par l'oxalate d'ammonium ; nous n'avons malheureusement pas dosé la teneur en acides uroniques.

$\mathrm{La}$ fraction hémicelluloses, c'est-à-dire les polyholosides dissous par $\mathrm{SO}_{4} \mathrm{H}_{2}$ dilué $(5 \mathrm{p}$. 100 pendant 3 heures à l'ébullition) est relativement constante, de 5 à $6 \mathrm{p}$. 100 de la matière sèche environ (tabl. I). Elle est constituée de façon très constante par 65 à 70 p. 1oo d'arabanes, 25 p. 10o d'hexosanes (presque exclusivement de galactanes) et 5-1o p. too de xylanes. Cette composition est très différente de celle des hémicelluloses des organes aériens des plantes fourragères, dans lesquelles prédominent les xylanes (JARRIGE, I963). 
La fraction cellulose est pratiquement pure ; elle ne contient pas de xylanes résiduels. Elle a tendance à diminuer quand les teneurs en matière sèche et en saccharose augmentent. Il en est de même pour la teneur en lignine brute; la proportion de celle-ci dans les membranes tombe de Io-I 2 p. Ioo à 6-7 p. Ioo approximativement. Les teneurs en cellulose brute Weende n'ont pas été dosées mais celles qui sont le plus généralement rapportées sont de $6 \mathrm{p}$. roo pour les betteraves à sucre et de $8 \mathrm{p}$. Ioo pour les betteraves fourragères; elles sont donc sensiblement supérieures à la somme cellulose + lignine.

\section{TABLEAU I}

Teneur des principaux constituants glucidiques

(en p. Ioo de la teneur en matière sèche)

\begin{tabular}{|c|c|c|c|c|c|c|}
\hline Type & Fourr & gère & $\begin{array}{l}\text { For } \\
\text { riche }\end{array}$ & $\begin{array}{l}\text { agère } \\
\text { n MS }\end{array}$ & Sucrière & Potagère \\
\hline Variété & Eckendorf & $\begin{array}{l}\text { Barres } \\
\text { Strino }\end{array}$ & $\begin{array}{c}\text { Red } \\
\text { Otofte }\end{array}$ & Hunsballe & $K \ddot{u h n}$ & $\begin{array}{l}\text { (Chair } \\
\text { rouge) }\end{array}$ \\
\hline Teneur en matière sèche & 10 & 10 & 17,5 & 19,5 & 23 & 12,5 \\
\hline $\begin{array}{l}\text { Sucres réducteurs } \ldots \ldots \ldots \ldots \ldots \\
\text { Saccharose } \ldots \ldots \ldots \ldots \ldots \ldots \ldots \\
\text { Sucres totaux } \ldots \ldots \ldots \ldots \ldots \ldots\end{array}$ & $\begin{array}{l}12,2 \\
45,7 \\
57,9\end{array}$ & $\begin{array}{r}5,1 \\
58,2 \\
63,3\end{array}$ & $\begin{array}{r}0,9 \\
64,8 \\
65,7\end{array}$ & $\begin{array}{r}0,4 \\
67,0 \\
67,4\end{array}$ & $\begin{array}{r}0,6 \\
68,7 \\
69,3\end{array}$ & $\begin{array}{r}1,2 \\
50,7 \\
51,9\end{array}$ \\
\hline $\begin{array}{l}\text { Extrait aqueux } \ldots \ldots \ldots \ldots \ldots \\
\text { Extrait par oxalate } \mathrm{NH}_{4} \ldots \ldots\end{array}$ & $\begin{array}{r}77,9 \\
3,4\end{array}$ & $\begin{array}{r}78,4 \\
3,5\end{array}$ & $\begin{array}{r}83,3 \\
2,8\end{array}$ & $\begin{array}{r}84,7 \\
2,2\end{array}$ & $\begin{array}{r}80,7 \\
2,9\end{array}$ & $\begin{array}{r}75,6 \\
6,5\end{array}$ \\
\hline 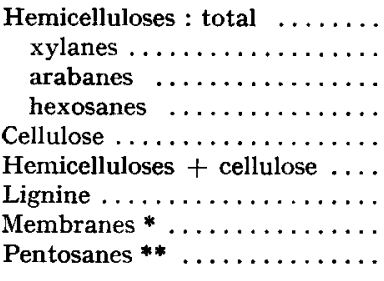 & $\begin{array}{r}5,5 \\
0,6 \\
3,5 \\
1,4 \\
6,5 \\
12,0 \\
1,4 \\
13,4 \\
6,4\end{array}$ & $\begin{array}{r}5,5 \\
0,4 \\
3,6 \\
1,5 \\
6,0 \\
11,5 \\
1,4 \\
12,9 \\
7,4\end{array}$ & $\begin{array}{l}4,7 \\
0,4 \\
3,3 \\
1,0 \\
4,3 \\
9,0 \\
0,7 \\
9,7 \\
5,7\end{array}$ & $\begin{array}{l}5,0 \\
0,4 \\
3,3 \\
1,3 \\
3,6 \\
8,6 \\
0,5 \\
9,1 \\
5,5\end{array}$ & $\begin{array}{r}5,8 \\
0,4 \\
3,9 \\
1,5 \\
4,4 \\
10,2 \\
0,7 \\
10,9 \\
7,0\end{array}$ & $\begin{array}{r}6,2 \\
0,3 \\
4,3 \\
1,6 \\
5,0 \\
11,2 \\
0,7 \\
11,9 \\
8,1\end{array}$ \\
\hline
\end{tabular}

* Somme hemicelluloses + cellulose + lignine.

** Pentosanes dosés par la méthode classique de distillation chlorhydrique.

La teneur en pentosanes (xylanes + arabanes) dosée après séparation chromatographique est nettement inférieure à la teneur en pentosanes estimée à partir du furfural obtenu par distillation chlorhydrique. Les dosages effectués sur le résidu aqueux avant et après le traitement par l'oxalate donnent respectivement 5,6 et 3,9 p. Too de la matière sèche pour la variété Red Otofte, 7,o et 5,4 pour la variété $K u ̈ h n$.

La composition de la fraction polysaccharidique des membranes, hémicelluloses + cellulose, est très différente de celle des organes aériens des plantes fourragères (JARRIGE, I963); elle est caractérisée par une proportion élevée d'arabanes (30 à $3^{8} \mathrm{p}$. Ioo) et une faible proportion de xylanes ( 4 à 5 p. 100); les proportions d'arabanes et de pentosanes (arabanes + xylanes) augmentent alors que celles de la cellulose et des hexosanes (cellulose + hexosanes des hémicelluloses) diminuent quand la teneur en saccharose s'accroît; en conséquence le rapport pentosanes/hexosanes 
passe approximativement de 0,50 à 0,75 . La composition que nous observons pour les membranes. des betteraves les plus riches en sucres doit refléter celle des membranes du parenchyme de réserv'* Il est regrettable que nous n'ayons pas dosé les acides uroniques mais nous ne disposions pas de méthode satisfaisante à l'époque.

\section{Constituants azotés}

La teneur en azote total (tabl. 2) est sensiblement supérieure à celle qui est la plus généralement rapportée (cf. Becker et NEHRING, I969). Elle a tendance à diminuer lorsque la teneur en sucres augmente; elle est environ deux fois plus élevée pour la variété potagère.

\section{TABLEAU 2}

Teneur et répartition de l'azote

(les acides aminés et amides libres sont exprimés en p. Ioo de la somme de ces constituants)

\begin{tabular}{|c|c|c|c|c|c|c|}
\hline Type & \multicolumn{2}{|c|}{ Fourragère } & \multicolumn{2}{|c|}{$\begin{array}{l}\text { Fourragère } \\
\text { riche en MS }\end{array}$} & \multirow{2}{*}{ Sucrière } & \multirow{2}{*}{$\begin{array}{c}\text { Potagère } \\
-(\text { Chair } \\
\text { rouge) }\end{array}$} \\
\hline Variété & Eckendorf & $\begin{array}{l}\text { Barres } \\
\text { Strino }\end{array}$ & $\begin{array}{l}\text { Red } \\
\text { Otofte }\end{array}$ & Hunsballe & & \\
\hline $\begin{array}{c}\text { Azote total } \\
\text { (p. } 100 \text { de la matière sèche) }\end{array}$ & 1,38 & 1,48 & 1,20 & 1,08 & 1,24 & 2,52 \\
\hline $\begin{array}{l}\text { Répartition de l'azote } \\
\text { (p. } 100 \text { de l'azote total) }\end{array}$ & & & & & & \\
\hline Extrait éthanolique ........ & 81 & 71 & 71 & 79 & 72 & 83 \\
\hline Extrait aqueux $\ldots \ldots \ldots \ldots$ & 8 & 8 & 8 & 11 & 8 & 7 \\
\hline Résidu $\ldots \ldots \ldots \ldots \ldots \ldots$ & 11 & 21 & 21 & 10 & 20 & 10 \\
\hline Acides aminés libres & & & & & & \\
\hline Acide aspartique $\ldots \ldots \ldots \ldots$ & 7,4 & 4,4 & 7,9 & 9,5 & 5,6 & 4,3 \\
\hline Acide glutamique $\ldots \ldots \ldots$ & 14,6 & 15,4 & 15,2 & 7,5 & 13,6 & 14,4 \\
\hline Sérine $\ldots \ldots \ldots \ldots \ldots \ldots$ & 7,2 & 4,1 & 5,6 & 5,7 & 4,5 & 5,0 \\
\hline Glycine $\ldots \ldots \ldots \ldots \ldots \ldots$ & 0,8 & 0,9 & 0,8 & 0,8 & 0,3 & 0,9 \\
\hline Thréonine $\ldots \ldots \ldots \ldots \ldots$ & 2,3 & 1,6 & 1,6 & 1,5 & 1,2 & 1,7 \\
\hline Alanine $\ldots \ldots \ldots \ldots \ldots$ & 5,7 & 3,2 & 5,8 & 7,6 & 4,8 & 9,2 \\
\hline Asparagine $\ldots \ldots \ldots \ldots \ldots$ & 6,5 & 7,2 & 8,0 & 6,3 & 7,9 & 6,3 \\
\hline Glutamine $\ldots \ldots \ldots \ldots$ & 34,5 & 43,6 & 35,8 & 36,5 & 49,8 & 46,3 \\
\hline Tyrosine $\ldots \ldots \ldots \ldots \ldots$ & 1,2 & 2,0 & - & 1,8 & 1,0 & - \\
\hline Acide $\gamma$-amino-butyrique $\ldots \ldots$ & 9,2 & 8,3 & 8,5 & 9,5 & 6,3 & 4,4 \\
\hline Valine $\ldots \ldots \ldots \ldots \ldots \ldots \ldots$ & 1,6 & 1,9 & 2,5 & 2,7 & 1,6 & 1,7 \\
\hline $\begin{array}{r}\text { Leucine }+ \text { Phénylalanine }+ \\
\text { Isoleucine } \ldots \ldots \ldots \ldots \ldots\end{array}$ & 7,2 & 4,3 & 6,5 & 6,0 & 4,3 & 4,6 \\
\hline Lysine $\ldots \ldots \ldots \ldots \ldots \ldots$ & traces & traces & traces & 0,6 & traces & traces \\
\hline
\end{tabular}

La répartition de l'azote total, semblable d'une variété à l'autre, est particulièrement caractéristique : de 7 I à 8 I p. Ioo sous forme de constituants éthanolosolubles, acides aminés libres et amides, de 7 à 8 p. Ioo sous forme de peptides extraits par l'eau après traitement par l'éthanol et seulement de Io à 2 I p. Ioo sous forme de protéines.

L'ensemble des acides aminés et amides libres recouvrés dans l'éluat à la sortie de la colonne 
représente environ $80 \mathrm{p}$. Ioo de l'azote de l'extrait éthanolique (de 72 à 87 p. roo suivant les variétés). Sa répartition (tabl. 2) est caractéristique des betteraves (FAUCoNNEAU, 1960). La glutamine représente pratiquement de 35 à $5 \circ \mathrm{p}$. Ioo de la somme des constituants ainsi séparés ; l'asparagine est beaucoup moins importante $(6,3$ à 8,0 p. 100). La fraction des acides aminés libres est caractérisée par l'importance de l'acide glutamique et la faible teneur de tous les acides aminés essentiels ; la lysine n'est présente qu'à l'état de traces. La somme des constituants non identifiés de l'extrait éthanolique et de ceux de l'extrait aqueux, que nous n'avons pas analysés, représente en moyenne 23,6 p. roo de l'azote total (de 2 I à 28 p. Ioo suivant les variétés); il s'agit en partie de peptides.

La composition des protéines contenues dans le résidu de la double extraction éthanolique et aqueuse a fait l'objet d'une étude ultérieure (Pron, communication personnelle) sur des variétés fourragères riches en matière sèche, à l'aide de la méthode de détermination des acides aminés sur colonne d'échangeur d'ions (PION et de Belsunce, I96I). Elle est relativement semblable à celle des protéines des feuilles et des tiges des graminées ou de la luzerne (cf. Fauconneau et Pron, 1965) ; cependant, les teneurs en lysine et, à un degré moindre, en isoleucine, phénylalanine et arginine sont sensiblement plus faibles. La composition en acides aminés indispensables des protéines de la betterave est donc bien équilibrée mais la composition des matières azotées totales est beaucoup moins intéressante pour le monogastrique (porc) à cause de la proportion importante d'acides aminés non indispensables et d'amides sous forme libre.

Reçu pour publication en octobre 1972.

\section{SUMMARY}

\section{NOTE ON THE CARBOHYDRATE AND NITROGEN CONSTITUEN'TS IN DIFFERENT TYPES OF BEET ROOTS}

Using paper chromatography techniques, the sugars of the principal carbohydrate fractions (table r) and the free amino acids and amides were determined (table 2 ) in the roots of six varieties of beets : two mangolds, two fodder-beets, one sugar-beet and one garden-beet.

The saccharose content increased with increase in the dry matter content, while the reducing sugars content decreased. The hemicellulose fraction (4.7-6.2 p. Ioo of dry matter) was characterized by a very high proportion of arabinose. The true cellulose content decreased with increase in the saccharose and dry matter contents.

Distribution of total nitrogen was about the same for the six varieties : ethanolo-soluble constituents (free amino acids and amides) : $7 \mathrm{I}-8 \mathrm{I}$ p. 100 ; water-soluble peptides extracted after the ethanol treatment : 7-8 p. IOO ; proteins : IO-2I p. IOO. The pool of free amino acids and amides was characterized by a preponderance of glutamine $\left(35^{\circ}-\mathrm{p}\right.$. 100) and a low percentage of essential amino acids.

\section{RÉFÉRENCES BIBLIOGRAPHIQUES}

Becker M., Nehring K., I969. Handbuch Der Futtermittel, vol. I, 389-41o. Éd. Paul Parey.

Demarquilly C., I972. Digestibilité, valeur nutritive et ingestibilité des betteraves de différentes teneurs en matière sèche. Ann. Zootech., 21, 4I5-428.

Fauconneau G., r96o. Les fractions azotées et les acides organiques des graminées et des légumineuses. Proc. 8th Internat. Grassland Congr. Reading, I960, 6I7-620.

Fauconneau G., Pion R., 1965. Amido acid composition of proteins of some fodder plants. Proc. 9th Internat. Grassland Congr., Sao Paulo, 1965. Vol. I, 779-78r.

JARRIGe R., I96r. Analyse des constituants glucidiques des plantes fourragères. I. Fractionnement des constituants de la membrane par les hydrolyses acides. Ann. Biol. anim. Bioch. Biophys., 1, 163-212. 
JARRIGE R., r963. Les constituants membranaires des plantes fourragères. Ann. Biol. anim. Bioch. Biophys., 8, 143-190.

Pion R., De Bersunce C., 196r. Détermination des acides aminés de quelques aliments à l'aide de la méthode de Moore et Stein. Festschrift III, Intern. Tierzuchtkongr., Hamburg, I96r, I I6-II9.

Pion R., Fauconneau G., 1966. Les acides aminés des protéines alimentaires. Méthodes de dosage et résultats obtenus, Cahier $A . E . C, \mathrm{n}^{\circ} 6,155^{-1} 75$.

Rerat A., Henry Y., Ig64. Utilisation de la betterave danoise dans l'alimentation du porc en croissance. I. Recherche d'un plan de rationnement. Ann. Zootech., 13, $217-236$. 